\title{
Entrevista com o professor Enric Sullà Álvarez, especialista em canonicidade
}

\author{
Amanda Oliveira \\ Doutoranda em Teoria da Literatura pela PUCRS
}

$\diamond$

\begin{abstract}
$\mathrm{O}_{1}^{\mathrm{p}}$ Professor Enric Sullà Álvarez aposentou-se como Professor da Faculdade de Letras da Universidade Autônoma de Barcelona, no Departamento de Filologia Espanhola. Licenciado em Filosofia e Letras pela Universidade Autônoma de Barcelona e Doutor em Filologia Catalã pela mesma universidade. Participou como pesquisador de projetos sobre o pensamento literário espanhol do século XX. Orientou dezoito trabalhos de pesquisa de graduação, vinte e quatro de mestrado e seis de doutorado. Editou diversas obras e publicou uma série de capítulos de livros, artigos em revistas, além, dentre outros, das obras Una interpretació de les Elegies de Bierville de Carles Riba (1993), Teoría de la novela. Una antologia de textos del siglo XX (1996 y 2001) y El canon literario (1998).

A presente entrevista foi realizada durante sua participação no XI Seminário Internacional de História da Literatura, ocorrido de 06 a 08 de outubro de 2015, na PUCRS, onde proferiu a conferência de encerramento, intitulada "El canon y los clásicos ante la crisis de los grandes relatos", e o minicurso "El canon de los clásicos: historia, procesos, debates".
\end{abstract}

AMANDA - Quando comecei a estudar espanhol, aprendi que há quatro idiomas na Espanha, e que, na verdade, quando se fala vasco, catalão ou galego, o espanhol é o idioma estrangeiro, ou seja, que se aprende, por exemplo, o catalão, e o espanhol como outra língua. É, de fato, assim? Aprende-se espanhol como outro idioma?

- ENRIC - Vayamos por partes. Hoy en día el español y el catalán se estudian en los colegios, pero no se debe olvidar que, a consecuencia de la derrota militar de la II República Española a manos del general Franco, la enseñanza del catalán estuvo prohibida hasta 1979. Por citar mi caso, mis padres hablaban el catalán entre ellos, y así lo aprendí yo; también me ayudaron los escasos libros en esa lengua que había en casa, pero no pude estudiarlo hasta que fui a la universidad en 1968. En el colegio, sólo me enseñaron el español y en español. Una anécdota, en 1966, recuerdo que mi profesor de filosofía hablaba con nosotros, sus estudiantes, en catalán pero cuando tenía que empezar la clase, la daba en español con textos en español, aunque para mis compañeros y para mí entonces el español era el castellano.
AMANDA - Eu não iria iniciar nossa conversa com essa pregunta, mas me parece muito oportuna. Aprende-se o espanhol na escola, mas não é um corte na cultura "de casa"? Há uma diferença do falar galego para o falar espanhol, no sentido de língua oficial, de validação?

- ENRIC - La opinión pública dominante en España es que hay que hablar español porque es la lengua oficial del estado, y que con el español basta y sobra, que no hace falta hablar ninguna otra lengua. Pero en el País Vasco se habla euskera, en Galicia el gallego, y en Cataluña, Valencia y Mallorca, se hablan variantes de una lengua común que, solo por comodidad, denominaré catalán. Todas estas lenguas tienen la condición de "cooficiales" en los territorios donde se hablan. Pero hay que recordar otra vez que el uso público del catalán (y de todas esas lenguas) estuvo prohibido desde 1939 y solo se toleró su uso con fines culturales desde mediados de los sesenta. Cuando la democracia sucedió a la dictadura, hacia 1979, entró el catalán en la enseñanza pública. Desde luego, ha habido un proceso de normalización de las 
lenguas nacionales, importante pero limitado, porque el español mantiene la posición de lengua dominante por su presencia en los medios de comunicación, en la administración pública y en el mundo académico. En fin, que el catalán está en una posición claramente secundaria respecto al español. La irritación y la incomprensión de una gran parte de la opinión pública española surge del deseo de muchos ciudadanos de Cataluña por mantener y cultivar su lengua, de vivir en catalán.

Amanda - Pergunto porque quando se faz um estudo das primeiras manifestações literárias na América Latina, ou melhor, América Hispânica, como definia Pedro Henríquez Ureña, e pensando no texto de Ángel Rama, La ciudad letrada, a imposição dos idiomas português e espanhol para nós, latino-americanos, fezse para negar os outros tantos idiomas e dialetos que se falavam aqui. A dominação, segundo Rama, deu-se de duas formas: a física e a linguística. É o que acontece, por exemplo, na Espanha, quando temos essas línguas sendo utilizadas no mesmo ambiente?

จ ENRIC - Hubo prohibición oficial de la lengua y las instituciones catalanas entre 1923 y 1930, con la dictadura de Primo de Rivera; y, por supuesto, la hubo durante la dictadura de Franco, entre 1939 y 1975, y más allá de la muerte física del dictador, porque el sistema franquista no se desmontó hasta dos años más tarde. La dictadura reprimió mediante la violencia física y la prisión a los demócratas de cualquier orientación, a los obreros y a las minorías nacionalistas. Y, por supuesto, reprimió y controló la cultura mediante una censura fuerte, analfabeta pero muy fuerte; también ejerció la violencia lingüística y cultural contra vascos, gallegos y todas las comunidades catalanoparlantes.

AMANDA - O seu curso (ministrado durante o XI Seminário Internacional de História da Literatura, na PUCRS) terá como temática a canonicidade, o clássico, a tradição. $O$ que são esses conceitos se não imposições?

- ENRIC - Daré respuesta a esta pregunta mediante un ejemplo que exigirá que nos traslademos a Madrid. Hay una calle muy bonita en el Barrio de las Letras, en el Madrid antiguo. la calle de Las Huertas, que sale del Paseo del Prado, creo, y asciende hasta la Plaza del Angel. Pues bien, en el pavimento de esta calle hay transcritos pasajes de obras literarias. Uno es este: "En un lugar de la Mancha de cuyo nombre...". Bien, yo he andado por esta calle y he reconocido todos estos pasajes. Esos pasajes, esas citas, son la muestra, sencilla, pero monumentalizada, de un canon, de un canon posible. Ahí están. Que los viandantes les pasen por encima, que los pisen, es una anécdota, lo importante es que se han convertido en un monumento, en una referencia simbólica. No ocurre lo mismo en Cataluña. En Cataluña no tenemos clásicos, no porque carecer de obras o autores importantes, sino porque no tienen ese reconocimiento público, porque solo los conocen una minoría de ciudadanos catalanes. No tenemos una calle como esa, pero si la tuviéramos, si pusiéramos esos pasajes de obras, causarían sorpresa, porque no existe el poso cultural que permite ese reconocimiento. No ha habido los consensos, la acumulación de tradición histórica que haya permitido que dos ciudadanos catalanes mínimamente cultos reaccionen diciendo: "Ah, sí, ya sé de quién es esta cita”. Esa tradición no ha existido. ¿Por qué? Además de la larga historia de desatención estatal a la cultura catalana desde el Decreto de Nueva Planta de 1714, esta padeció, como ya he dicho, durante el siglo XX, dos dictaduras y una guerra. Se requiere tiempo, mucho tiempo, para que una comunidad pueda afirmar y consolidar una tradición cultural propia, viva y efectiva. La ciudad letrada catalana todavía está en construcción, y mucho me temo que en la actualidad está en crisis debido, entre otros factores, a la globalización.

Amanda - Ao ler alguns de seus textos, dois tópicos me chamaram a atenção, além das questões sobre o cânone, da tradição, do clássico: primeiro, o leitor; mesmo que não seja citado diretamente, me parece ser algo bastante cuidado de sua parte, até mesmo na forma de escrever seus artigos. A outra é a questão do pedagógico, do fazer docente dentro de sala de aula, $\mathrm{e}$ por isso me parece que esses dois pontos se entrecruzam, e são temáticas que por vezes nos faltam na Academia, como a preocupação da formação de um professor.

- ENRIC - Hay una relación en la respuesta a las dos preguntas: he sido profesor, sobre todo profesor, a lo largo de mi carrera académica. Al cabo de un año de terminar mis estudios, en 1974, me contrataron como profesor en la UAB. Mi preparación pedagógica era nula cuando me encontré en un aula con 130 alumnos, dando una lección que había preparado con mucha angustia; encima, minutos antes de terminar la clase, se me habían terminado las notas. Sufrí mucho, pero aprendí de colegas mayores, con la experiencia, y cometiendo errores, naturalmente. La preocupación por las clases es importante también porque he dado clases durante muchos años y, en particular, porque he explicado Teoría de la Literatura. Dar clase de Teoría es un suplicio porque siempre estás manejando abstracciones. El romanticismo es una abstracción, sí, pero los estudiantes están familiarizados con "lo romántico". Sin embrago, cuando se habla de técnicas literarias y su eficacia en un texto empiezan las dificultades. Surgen ahí dos problemas: uno es la necesidad de ser riguroso y preciso al exponer la teoría, procurar que las abstracciones se entiendan mediante explicaciones adecuadas y ejemplos concretos. 
Dado que en Teoría de la Literatura hay muchas opiniones, muchas ideas, muchos conceptos, dejar los términos claros dentro de un marco teórico determinado exige un notable esfuerzo por parte del profesor. El objetivo es que el estudiante entienda ideas y conceptos, y para eso hace falta un vocabulario riguroso, una argumentación clara y precisa. Otro problema es la aplicación de estos conceptos, hay que justificar "para qué sirven". Con los años, mi mayor preocupación mayor ha sido "¿qué puedo hacer yo para que los estudiantes, cuando termine este curso, se lleven algo consigo, se lleven herramientas que les sirvan para leer y explicar textos?".

Durante muchos años, he dado un curso de Teoría de la Narración. Una manera de dar ese curso es resumir, explicar teorías: este autor dice eso, este dice aquello, etc.; dar un curso erudito, dando noticia de muchos autores. $\mathrm{O}$ se puede proponer una selección de temas y problemas, siempre arriesgada y discutible, porque, claro, abundan y hay que escoger; pero sobre todo se trata de aplicar los conceptos escogidos a un texto. Con ello se persiguen dos objetivos: por un lado, enseñar a leer leyendo; y, por el otro, cuando se ha leído, tratar de explicar lo comprendido de una manera organizada, de una manera, digamos, racional, de tal manera que, ya no la persona que hace este trabajo, sino otra persona que lea este trabajo, vaya al texto y lo pueda entender. Como lector, agradezco que me expliquen asuntos difíciles con la mayor claridad, lo que no quiere decir que se renuncie a la complejidad. Hay que clarificar hasta donde se pueda. El objetivo pedagógico es ser claro pero también práctico, para que los estudiantes adquieran una competencia que les sirva para mi asignatura y para otras más.

\section{- AMANDA - Seria perceber e pensar a teoria como uma forma de ver melhor?}

- ENRIC - En los últimos años, se ha dejado de lado la Teoría de la Literatura y se ha hecho Teoría, sin más. El resultado es que la reflexión teórica se ha ensimismado, se ha cerrado sobre sí misma. Se podría decir que la Teoría ha dominado el discurso académico de las Humanidades. Eso ocurría al mismo tiempo que cambiaba el campo del saber y la literatura empezaba a perder la posición fundamental en la enseñanza y la cultura que ha ocupado durante gran parte del siglo XX, Ese cambio, todavía en curso, hace necesario repensar la función de los estudios literarios. Los excesos de la Teoría, al mismo tiempo que las resistencias que ha generado, exigen un balance de pérdidas y ganancias, preguntarse por el camino recorrido y, sobre todo, por los objetivos posibles.

\section{- AMANDa - A teoria define um cânone literário?}

- ENRIC - Si por canon entendemos una lista, una serie de nombres, sí hay un canon de la Teoría. Un ejemplo que viví personalmente: el año 90, tuve la suerte de asistir a la School of Criticism and Theory en la Universidad de Dartmouth, en los Estados Unidos. Allí coincidí con universitarios norteamericanos y europeos, muy brillantes todos; pues bien, cuando hablábamos, era manifiesto que teníamos especialidades muy diferentes. Lo que compartíamos, en cambio, era la Teoría. Ese fue el terreno común en el que llegamos a entendernos. Habíamos leído los mismos autores y, claro está, compartíamos las preocupaciones teóricas de aquel momento.

\section{- AMAnda - O cânone é elitista?}

- ENRIC - Para empezar el canon, en singular, no existe. El canon solo existe como concepto teórico. Lo que sí existe son los cánones, una serie histórica de realizaciones concretas de la idea de canon; incluso en una misma época coexisten cánones diferentes. En el sentido hoy corriente, los cánones son listas, selecciones de libros o de objetos culturales. En este aspecto, forman parte de la vida normal de una cultura. ¿Que si el canon es elitista? Por ejemplo, la lista de los diez discos más vendidos es un canon y no es elitista. ¿Por qué la lista de los diez libros más leídos de la literatura occidental sí lo es? No tiene por qué ser elitista. Esa idea procede de la "guerra del canon" que estalló en los Estados Unidos en los años 80 y 90, cuando se pretendió abrir el canon a obras escritas por mujeres y autores afroamericanos, lo que exigía cambiar los criterios de valor vigentes. Un canon puede ser elitista, pero otro puede no serlo. Hay que tener en cuenta siempre que no todo lo que se ha escrito tiene el mismo valor, ni todo merece la misma atención, ni se puede conservar todo. Una cultura tiene que seleccionar, tiene que escoger lo que le interesa conservar y estudiar. Y, por supuesto, escoge la sociedad, escogen los diferentes colectivos, escogen los individuos, todos nos pasamos el día escogiendo, en función de valores de los que no siempre somos conscientes.

Propongo un ejercicio muy simple: intentar, por escrito, privadamente, subjetivamente, enumerar los criterios de su juicio personal. Puedo adelantar que cuesta mucho, que es muy difícil. Sabemos lo que nos gusta, no porqué. Solemos creer, además, que nuestro gusto es solo nuestro, totalmente personal, pero muy a menudo lo que nos gusta le gusta también al vecino. Entonces nos damos cuenta que el gusto no es tan subjetivo, sino que está condicionados por situaciones sociales, culturales y económicas a menudo discriminatorias. El canon no es elitista en sí mismo, pero sí lo es el canon dominante y sobre todo la cultura a la que pertenece; donde se forja el elitismo es en el acceso a la cultura, en la posesión de la cultura necesaria para acceder a los textos literarios más exigentes. Siguiendo a Bourdieu, acceden a la cultura 
aquellos que tienen acceso al capital escolar, que exige a su vez capital económico; el dominio, la posesión, del canon les da, encima, capital simbólico. El jazz, por ejemplo, es hoy elitista, porque es una música para una minoría de iniciados, pero no siempre lo fue.

\section{- AMANDA - O problema, então, não é o cânone, mas o que o rege?}

- ENRIC - El canon no es, no debe ser un problema. Basta tener en cuenta que en la actualidad el canon se ha fragmentado y que coexisten cánones sectoriales (de la literatura de mujeres, por ejemplo), además de los cánones nacionales. Sí puede ser un problema quién administra el canon, quién se apropia del canon digamos dominante. Por ejemplo, ¿qué hace Harold Bloom? Con una audacia, una inteligencia y una oportunidad notables, escribe un libro que se titula El canon occidental, y no 26 autores que deberías leer antes de morir, que sería un título más adecuado. Según Bloom, el "canon occidental" son los autores que una persona culta debe conocer. Como buen estudioso de la literatura angloamericana, sitúa a Shakespeare en el centro de su canon. Un escritor español habría puesto Cervantes, lógicamente. Un italiano, a Dante. Entonces, ¿por qué debemos creer a Harold Bloom? Respeto su opinión, pero no tengo que creer lo que me dice. Es una de tantas propuestas, nada más. Por un lado sostiene que el canon no existe pero, por el otro, prescribe una lista de lecturas. Ahora bien, ¿qué autoridad tiene el libro de Bloom? No obliga a nada ni a nadie.

Esta es la diferencia entre el canon bíblico y el literario. La Iglesia tiene autoridad para dictar cómo se deben leer e interpretar las Sagradas Escrituras. No hay una autoridad semejante en el campo literario, la universidad no puede imponer nada. Lo que sí hace Bloom es defender un canon basado en criterios estéticos. Reconoce también que muchas obras son hoy difíciles de leer. Por eso la misión de los profesores de literatura es facilitar el acceso a los textos de sus estudiantes. Una misión cada vez más complicada porque, como he dicho, en el conjunto de la cultura, la literatura tiene cada vez menos peso. Basta ir a un quiosco de revistas y buscar las revistas de literatura: son muy pocas, en comparación otras áreas culturales, como el cine, el arte, etc.

- AMANDA - Falando sobre a função social da literatura e pensando sobre o Brasil: estudantes de literatura no país que há poucos leitores; 0 incentivo de cursos de graduação e de pós-graduação, aqui na PUCRS, para escrita criativa; o mito de que não se lê: mas na verdade se lê o que não é tão clássico, canônico, lê-se best sellers; as leituras obrigatórias da escola e as leituras que os alunos gostam de ler (John Green ou Machado de Assis?). Como o senhor percebe essas questões?

- ENRIC - Es más complicado que eso. Decir que a un lado están los clásicos y al otro la literatura comercial o de consumo, es una simplificación excesiva. La producción literaria es tan variada que es mejor representarla como un abanico que comprende desde las obras más experimentales, para un público minoritario, hasta las obras más sencillas, de lectura fácil para un público que solo busca diversión, pasando por la literatura de género (narrativa de ciencia ficción, policíaca, de aventuras, fantástica, etc.), incluyendo tanto los best sellers como la que se podría considerar literatura de segunda fila, es decir, obras de calidad digna pero que no merecen mayor consideración.

Daré un rodeo. No hace muchos años, los estudiantes cursaban la licenciatura en filología, para aprender a leer y escribir. Hoy, en España, estos estudiantes van a la Facultad de Comunicación porque quieren escribir guiones para cine y televisión, hacer periodismo. No se olvide que la salida de un estudiante de filología, de literatura, es la enseñanza. Y esa profesión ya no apetece a muchos. El prestigio profesional se ha desplazado de la literatura a la televisión y el cine, artes más actuales y en las que se cree que es posible ganar mucho dinero y prestigio. En esta situación, los cursos de escritura creativa demuestran que aún hay personas que quieren escribir, que aún existe la necesidad de escribir para expresarse. Pero también debe tenerse en cuenta que una parte de la producción de las Escuelas de Letras o de Escritura Creativa se desplazando, por razones comerciales, hacia el campo de producción masivo.

Para terminar, mantengo que la pregunta fundamental es “¿qué hacer con la literatura?”. Aunque nadie discute su existencia, crecen las dudas sobre su función en el mundo de hoy, en la cultura contemporánea. Ese es un problema que aumenta con la distancia temporal, con las dificultades que suscitan unas referencias culturales que se desconocen, con una lengua compleja y a veces incomprensible, con unas convenciones formales que resultan extrañas, con una experiencia emocional o psicológica que cuesta compartir. Así las cosas, si no se quiere renunciar a los clásicos, hay que preguntarse cómo enseñarlos, cómo lograr que los estudiantes se interesen por ellos, cómo hacerlos vivos y cercanos. Si la función del canon es, por un lado, conservar, por el otro, es acercar, actualizar. Para una y otra función, hace falta leer, y a leer deben enseñar los profesores de literatura. 